\title{
LETRAMENTOS E MÍdIAS NA FORMAÇÃO CONTINUADA DE PROFESSORES UNIVERSITÁRIOS
}

\author{
ALFABETIZACIÓN Y MEDIOS DE COMUNICACIÓN EN LA FORMACIÓN \\ CONTINUA DE PROFESORES UNIVERSITARIOS
}

\author{
LITERACIES AND MEDIA IN CONTINUOUS TRAINING OF UNIVERSITY \\ TEACHERS
}

\author{
Dulce Márcia CRUZ ${ }^{1}$
}

\begin{abstract}
RESUMO: Esta pesquisa buscou identificar como o perfil midiático do professor que usa mídias digitais e o ambiente Moodle numa universidade do sul do país pode ser alterado a partir da oferta de disciplinas de formação continuada. O referencial teórico teve como base a formação docente reflexiva e os estudos sobre letramentos. A pesquisa qualitativa levantou dados iniciais e finais do perfil midiático de 218 docentes iniciantes em dois cursos ministrados no intervalo de três anos, e identificou os fatores que são considerados pelos professores para adotar ou refutar as mídias e o Moodle em suas práticas didáticas. O perfil midiático que apareceu na pesquisa é o de profissionais abertos às inovações, com confiança e disposição e que incorporaram novas maneiras de ensinar com as mídias a partir dos cursos. No entanto, lhes falta apoio institucional que considere o trabalho extra que implica a inclusão das mídias e condições propícias e desafiantes para ampliação dos seus letramentos em práticas pedagógicas significativas.
\end{abstract}

PALAVRAS-CHAVE: Mídias. Letramentos. Formação continuada.

RESUMEN: Esta investigación buscó identificar cómo el perfil mediático del profesor que usa medios digitales y el ambiente Moodle en una universidad del sur del país puede ser alterado a partir de la oferta de disciplinas de formación continuada. El referencial teórico tuvo como base la formación docente reflexiva y los estudios sobre alfabetización. La investigación cualitativa levantó datos iniciales y finales del perfil mediático de los cursos impartidos para 218 docentes iniciantes en dos cursos, con intervalo de tres años, e identificó los factores que son considerados por los profesores para adoptar o refutar los medios y el Moodle en sus prácticas didácticas. El perfil mediático que apareció en la investigación es el de profesionales abiertos a las innovaciones, con confianza y disposición y que incorporaron nuevas maneras de enseñar con los medios a partir de los cursos. Sin embargo, les falta apoyo institucional que considere el trabajo extra que implica la inclusión de los medios y condiciones propicias y desafiantes para ampliar su alfabetización mediática en prácticas pedagógicas significativas.

PALABRAS CLAVES: Medios. Alfabetización. Educación continuada.

${ }^{1}$ Universidade Federal de Santa Catarina (UFSC), Florianópolis - SC - Brasil. Doutora. Professora Associada do Departamento de Metodologia de Ensino e do Programa de Pós-Graduação em Educação. Líder do grupo de pesquisa EDUMÍDIA - Educação, Comunicação e Mídias. ORCID: http://orcid.org/0000-0001-7055-0137. Email: dulce.marcia@gmail.com

RIAEE - Revista Ibero-Americana de Estudos em Educação, Araraquara, v. 14, n. 4, p. 2175-2188, out./dez., 2019. e-ISSN: 1982-5587. 
ABSTRACT: This research aimed to identify how the media profile of the teacher using digital media and the Moodle environment in a university in the south of the country can be altered from the offer of continuing education subjects. The theoretical reference was based on reflexive teacher training and studies on literacies. The qualitative research raised initial and final data of the media profile of the courses taught to 218 beginning teachers in two courses, with interval of three years, and identified the factors that are considered by the teachers to adopt or refuse the media and Moodle in their didactic practices. The media profile that appeared in the survey is that of professionals who are open to innovation, with confidence and willingness, and who have incorporated new ways of teaching with the media from the courses. However, they lack institutional support that considers the extra work that implies the inclusion of appropriate and challenging media and conditions to expand their literacy in meaningful pedagogical practices.

KEYWORDS: Media. Literacies. Continuing education.

\section{Introdução}

Este texto descreve parte de uma pesquisa que buscou estudar se é possível ampliar os letramentos de professores de uma universidade pública brasileira através da formação para as mídias. O objetivo da pesquisa foi oferecer de modo sistemático cursos de formação docente continuada, em serviço, visando desenvolver uma metodologia que permitisse captar a reflexão em grupo e colaborativa dos professores universitários sobre a apropriação das práticas e linguagens da cultura digital (CRUZ, 2015). Esse objetivo se justifica na afirmação de Kenski (2015, p. 12) de que "a urgência de propostas inovadoras para a formação de qualidade precisa ser prioritária para a atualização didática digital dos professores que atuam nos cursos superiores".

Esta investigação se insere em um contexto mundial em que as tecnologias digitais e suas lógicas invadem os espaços privados e públicos, reconfigurando tempos e espaços, especialmente a relação com o conhecimento, seus modos de acesso, produção e disseminação (BUCKINGHAM, 2010). No espaço escolar, o papel da mediação pedagógica é entendido como a atitude e o comportamento do professor ao apresentar e tratar o conteúdo ou tema, visando ajudar o aprendiz a lidar com as informações até produzir conhecimento que o ajude a compreender e mesmo a interferir em sua realidade, tentando trazer sentido à educação, tanto para docentes como para estudantes (CRUZ, prelo; CRUZ, 2013).

A mediação pedagógica (CRUZ, prelo; CRUZ, 2015) visa emancipar o aluno a partir de estratégias e técnicas planejadas, de modo a colocá-lo no foco, ou seja, priorizando os objetivos de aprendizagem e não os de ensino. Pressupõe uma alteração na atitude do professor, de sua posição segura de comunicador e transmissor que tudo sabe, para o papel de 
orientação, de consultor, de facilitador e colaborador, que busca dinamizar a aprendizagem do aluno, trabalhando em equipe junto com ele, colocando o peso maior em sua responsabilidade pelo processo de aprendizagem. Em termos práticos, essa nova atitude e comportamento vão implicar na alteração do uso das tecnologias que não poderão mais privilegiar as aulas expositivas e os recursos audiovisuais voltados à transmissão de informações ou conhecimentos, experiências ou técnicas, mas estarão direcionados a fazer com que os alunos aprendam, de forma variada e adequada. Tais técnicas precisarão ser coerentes com os novos papéis de fortalecimento do aluno, de incentivo à sua participação e interação entre pares, favorecendo todas as atividades que privilegiem a produção de conhecimento, colaborativo e em equipe, de forma variada, para responder aos diferentes ritmos e formas de aprendizagem (ROJO, 2012).

Nessa aprendizagem, a formação docente precisa se dar como uma apropriação das práticas e linguagens da cultura digital nos níveis técnico, prático e crítico, no sentido que lhe dá Zeichner (1993). No nível técnico há uma aplicação do conhecimento educacional de forma eficiente e efetiva. É verificado o quê o professor faz em sala de aula e como o faz. No nível prático são levados em consideração os objetivos do ensino/aprendizagem e seus resultados. Finalmente, o nível crítico engloba a reflexão técnica e a prática, considerando o contexto social que afeta o ensino, por exemplo, questões políticas e culturais. Nessa perspectiva de formação, o foco muda do que é feito pelo professor e como é feito, para porque algo é feito em sala de aula. Para Zeichner, a reflexão crítica pode fazer com que os professores compreendam o ensino/aprendizagem e seu contexto social, bem como as influências desse contexto no ensino/aprendizagem. Assim, pode-se perceber que Zeichner entende a reflexão como prática social e política. Para Pimenta (2009, p. 31), "essa perspectiva apresenta um novo paradigma sobre formação docente e suas implicações sobre a profissão docente". Pimenta afirma que "desenvolver pesquisas nessa tendência implica posições político-educacionais que apostam nos professores como prática social" (2009, p. $31)$.

Para dar conta desses desafios, o objetivo da educação mediática de acordo com Buckingham (2010), não é desenvolver habilidades técnicas, nem promover apenas a autoexpressão, mas estimular uma compreensão mais sistemática de como funciona a mídia e, a partir daí, promover formas mais reflexivas de usá-la, contestando o uso instrumental da tecnologia como auxílio pedagógico transparente e neutro.

A questão que se apresenta na formação do professor midiático nessas novas condições é que, ao contrário do que se pensava com relação às tecnologias de comunicação e 
educação, na sociedade em rede, as mídias digitais são muito mais complexas, envolvendo leitura e escrita de gêneros não apenas textuais, mas multimodais, o que implica em novos letramentos (ROJO, 2012). Para Lemke (2010), os letramentos são sempre sociais, fruto da nossa participação nas relações em sociedade com significados historicamente desenvolvidos e atribuídos a partir de uma construção em rede. Se as práticas sociais moldam e transformam as mídias e suas linguagens possíveis, num processo recíproco e múltiplo, elas podem ser entendidas como multiletramentos: interativos, colaborativos, que questionam e modificam as relações de poder, especialmente as de autoria, e "são híbridos, fronteiriços, mestiços (de linguagens, modos, mídias e culturas)" (ROJO, 2012, p. 23). Por sua qualidade transgressora, os multiletramentos pedem uma nova ética e várias estéticas que comporiam os letramentos críticos (ROJO, 2012).

Essa introdução problematiza as dificuldades dos professores, em especial dos universitários, de letrar-se para as práticas midiáticas da cultura digital. Como as universidades são mais rapidamente afetadas pelas inovações tecnológicas, seus professores têm sido confrontados com a necessidade de incluir esses novos letramentos em suas práticas cotidianas, sem que haja uma formação voltada para isso. A adoção de ambientes virtuais de ensino e aprendizagem no ensino presencial a partir do final da década de 1990, por exemplo, fez de algumas universidades brasileiras um espaço de conflito (KENSKI, 2015). Por um lado, foi acelerada a criação de rotinas administrativas e de gestão do ensino conduzidas por uma crescente digitalização dos processos e usos de plataformas online, levando tanto à virtualização e ubiquidade do exercício profissional como a uma elevação da carga de trabalho fora do expediente acadêmico. Por outro lado, com a popularização da cultura digital nas práticas cotidianas cresceu a demanda por uma ampliação do conhecimento da sociedade de modo geral sobre como utilizar as mídias digitais na educação, baseadas numa presença cada vez mais expressiva destas na vida de professores e estudantes (KENKSI, 2015).

Neste sentido, a justificativa principal para a realização desta pesquisa era que a adoção do Moodle, alavancada pelos cursos de educação a distância criados pela Universidade Aberta do Brasil (UAB), traria desafios para o ensino presencial, implicando num processo de inovação (ROGERS, 1983) não só com potencial para modificar rotinas, práticas e estruturas que não tinham sido criadas para abrigar as características e demandas da modalidade semipresencial, mas, principalmente, para mudar a cultura docente do ensino presencial.

A partir dessa problemática, este projeto teve como objetivo investigar como professores universitários iniciantes da Universidade Federal de Santa Catarina (UFSC) se 
apropriavam e percebiam as mudanças que ocorriam nas suas práticas pedagógicas como consequência da formação continuada para as mídias digitais e para a plataforma Moodle, no ensino presencial (CRUZ, 2015). A parte da pesquisa qualitativa descrita neste artigo levantou dados iniciais e finais do perfil midiático de 218 docentes, identificando os fatores considerados por eles para adoção ou não das mídias e do Moodle em suas práticas pedagógicas, confrontando com o aprendido na formação continuada, realizada de forma inovadora de modo híbrido, com turmas presenciais e a distância.

\section{Desenvolvimento}

Para estudar a formação docente para as mídias na instituição foram traçadas duas frentes de coleta: 1) as oficinas voltadas à aprendizagem do ambiente virtual de ensino e aprendizagem; e 2) a oferta de uma disciplina de formação para as mídias durante a pesquisa, em duas edições (em 2011-2: Linguagem audiovisual na educação presencial e a distância; em 2014-2: O Uso de Mídias Digitais na Prática Docente), cujos resultados serão descritos aqui.

A oferta das disciplinas aconteceu dentro do PROFOR, uma instância de formação continuada ligada à Reitoria da UFSC para capacitação dos novos professores em estágio probatório, e possibilitou criar algumas situações de aprendizagem e verificação dos letramentos, bem como dos processos de adoção percebidos pelos docentes. Foram aplicados questionários de levantamento de perfil que tinham função de verificar o letramento dos professores e sua disposição para a aprendizagem do uso das mídias na educação. No final de cada disciplina, foram aplicados questionários visando não apenas avaliar a oferta, mas também a percepção do que foi aprendido e, se possível, do que tinha sido incorporado pela formação em práticas de sala de aula com as mídias. Os questionários foram construídos e aplicados on-line. Em 2011, através do LimeSurvey e, em 2014, com os formulários do Google. Estes questionários permitiram o preenchimento on-line e tiveram sua tabulação facilitada pelos mecanismos dos próprios programas.

\section{Letramentos e uso das mídias pelos professores participantes da disciplina de 2011-2 - Linguagem audiovisual na educação presencial e a distância}

A disciplina "Linguagem audiovisual na educação presencial e a distância" foi oferecida no segundo semestre de 2011, e sua ementa abordava os seguintes temas, com foco na aprendizagem, linguagens e produção de material didático para as mídias: Novos paradigmas do conhecimento e sua relação com o processo ensino/aprendizagem: o papel do 
professor diante das tecnologias de comunicação e informação. Características fundamentais da linguagem audiovisual e hipermidiática. Descrição das mídias, suas características, limitações e possibilidades no apoio ao processo de ensino e aprendizagem. Processos de produção da linguagem audiovisual e hipermidiática na educação presencial e a distância.

As duas turmas da disciplina de 2011 serão aqui denominadas como 'P', formada por 40 professores matriculados da oferta presencial, e 'D', pelos 22 matriculados para o curso a distância, num total de 62. Foi aplicado um questionário inicial, online, para traçar um perfil e saber de suas expectativas com relação à disciplina. Na turma $\mathrm{P}$ foram 40 alunos matriculados, dos quais 25 responderam ao questionário, e na turma D, dos 22 alunos matriculados, 19 responderam ao questionário. O perfil mostrou que a turma presencial era mais heterogênea, com um grande grupo com oito a 15 anos de experiência, enquanto na turma a distância a maioria estava mais ou menos equilibrada, na faixa de até oito anos de docência.

Em duas perguntas abertas foi pedido aos professores que citassem livremente as vantagens e desvantagens que percebiam do uso das mídias em sala de aula. Na primeira questão não houve uma distinção significativa nas percepções das duas turmas. As vantagens mais citadas foram comunicação e dinâmica, seguidas de agilidade, maiores possibilidades, interatividade, facilidade, bem como dinamismo, criatividade, atualização, diferentes propostas de aprendizagem, articular e auxílio na aprendizagem.

Nas respostas sobre a percepção das desvantagens do uso das mídias em sala de aula sobressaiu a questão tempo do preparo, que teve uma grande incidência, mostrando sua importância como limitador da adoção pelos professores. Não houve uma maior predominância entre as outras palavras citadas. A palavra "falta" foi recorrente e essa noção também pode ser associada nas referências às condições de trabalho, infra-estrutura, formação ou informação, tanto por razões técnicas (equipamentos, tecnologias) como pessoais (dificuldades, utilização, conhecimento, complexidade) ou mesmo culturais (linguagem midiática, interesse dos alunos).

Pelas respostas, a maior parte dos professores entendia que as mídias na sala de aula dinamizam e agilizam o processo de aprendizagem, que é uma forma diferente e atualizada de ensinar e que favorecem a comunicação entre professores, alunos e conteúdos didáticos. A grande desvantagem estava no tempo necessário para o preparo de mídias com os conteúdos de aula ou o de pesquisa de materiais midiáticos prontos para serem usados. Além da insegurança do professor, com relação à infra-estrutura oferecida em sala de aula pelas instituições, muitos se declararam não aptos a tal integração. No entanto, mesmo com essas 
desvantagens, para a pergunta "No seu entender, as mídias (técnicas e linguagens) são compatíveis ou não com suas práticas, experiências e necessidades como professor/a?", a turma $\mathrm{P}$ respondeu $96 \%$ que sim e a turma $\mathrm{D}, 84 \%$.

Ao serem questionados sobre quais as dificuldades para utilizar as mídias em suas aulas e como estavam resolvendo esses problemas, muitos responderam que não tinham problema. Dentre os que responderam afirmativamente e informaram como tentam resolver, as questões e soluções foram variadas. Pelas respostas apareceu forte a preocupação com a aceitação por parte dos alunos, enquanto apenas um professor alegou que recorre a colegas para tirar dúvidas. No entanto, na pergunta seguinte sobre a importância dada à troca de experiência com outros colegas docentes para o desenvolvimento de habilidades no uso das mídias na educação, as palavras mais citadas foram troca de experiências, importante $e$ fundamental. Sem que houvesse uma mais citada, algumas palavras que descrevem essas percepções podem ser ressaltadas: autodidatas, compartilhamento, colaboração, informação e algumas expressões como recorrer a colegas, trocar ideias.

Com relação ao papel da formação no processo de adoção, apenas uma resposta foi negativa quanto à importância da formação docente para o desenvolvimento de habilidades no uso de mídias na educação. As respostas positivas citaram o fato de que ela permite uma melhoria da aula e que há uma necessidade de mais prática e menos de teoria.

A questão seguinte buscava a percepção dos professores sobre seu letramento midiático: “qual estágio de adoção das mídias na educação você se encontra?” Tanto na turma presencial como na distância, o grupo maior de professores era o que considerava ter experiência por tentativas freqüentes. No entanto, na turma a distância, os professores que afirmaram estar na fase dos "contatos iniciais" ou de ter "interesse, mas ainda não ser usuário", era maior do que no grupo presencial. Pelo perfil levantado, o grupo a distância era mais jovem e tinha menos experiência na docência no ensino superior, o que pode ter pesado como parâmetro para as respostas.

Como era um questionário sobre expectativa e necessidades de formação para as mídias, foi apresentada uma lista de quais programas ou ferramentas os professores gostariam de aprender. Na turma presencial houve uma distribuição de cerca de 30\% de respostas para Powerpoint, vídeos do Youtube, exercícios on-line e ambiente virtual. Na turma a distância, o Powerpoint ainda era novidade, mas conhecer o ambiente virtual foi a opção mais citada (63\%). Essa carência de informação ficou mais evidente quando as ferramentas em questão eram do Moodle, o ambiente virtual adotado pela instituição na educação presencial e a distância. Na turma presencial, a ferramenta notas foi a mais citada (33\%), enquanto no grupo 
a distância, muitas apresentaram taxas maiores de 30\%, sendo que $68 \%$ gostaria de conhecer mais a ferramenta Tarefas e 57\% a Enquete. Uma hipótese para a baixa porcentagem das respostas na turma presencial e o inverso nos campi pode estar no fato de os docentes do campus central terem tido ofertas de oficinas de Moodle, enquanto para os docentes a distância isso até aquele momento não tinha acontecido.

Terminada a disciplina, foi enviado aos professores um questionário de avaliação para verificar se tinham utilizado as mídias apresentadas na formação em suas aulas durante o semestre. Não houve respostas para a opção "usei e não gostei". Os maiores índices de rejeição indicados pela resposta "não usei" foram para a ferramenta Hot Potatoes $(\mathrm{P}=80 \%$ e $\mathrm{D}=76 \%)$ e para a de criação de Avatares $(\mathrm{P}=65 \%$ e $\mathrm{D}=71 \%)$. Na resposta "usei e não tenho comentários", os maiores índices ficaram para PowerPoint, Fórum de Discussão e Tarefas. Para a afirmação "Usei e foi bom", a turma presencial citou Pesquisas em múltiplas ferramentas do Google (50\%), PowerPoint (42\%), Youtube e Video (30\%), enquanto os professores da turma a distância utilizaram bastante o Fórum de Discussão (47\%) e a Tarefas (41\%), ambas do Moodle. Na afirmação "usei e foi ótimo", os professores citaram igualmente na faixa dos $30 \%$ o PowerPoint, video e Youtube, enquanto a ferramenta Tarefas foi mais citada pela turma presencial (43\%).

De modo geral, as respostas apontaram que os professores de alguma maneira aplicaram o que foi mostrado durante a disciplina e ficaram satisfeitos com os testes, pois não rejeitaram nenhuma mídia experimentada, já que não houve respostas para a opção "usei e não gostei”. Os dados indicam que as características vantagem relativa e compatibilidade (ROGERS, 1983), pesaram a favor das Pesquisas em múltiplas ferramentas do Google; do vídeo; do PowerPoint e das Tarefas; a vantagem da comunicação para o Fórum de discussão (muito utilizado na disciplina dentro do Moodle), enquanto a complexidade e grau de experimentação pode ter pesado contra as ferramentas rejeitadas Hot Potatoes e criação de Avatares.

Nas questões voltadas a avaliar a disciplina e o quanto ela colaborou para uma maior compreensão das mídias, a tabela mostra as respostas positivas dos professores referentes à opção "concordo com a afirmação". 
Tabela 1 - Avaliação da disciplina para percepção sobre as mídias

\begin{tabular}{|l|c|c|}
\hline & Presencial & Distância \\
\hline Percebi mais vantagens no uso das mídias na educação & $87 \%$ & $83 \%$ \\
\hline $\begin{array}{l}\text { Percebi com maior clareza as limitações do uso das mídias na } \\
\text { educação }\end{array}$ & $73 \%$ & $71 \%$ \\
\hline $\begin{array}{l}\text { Percebi as possibilidades de soluções sobre as limitações das mídias } \\
\text { Minha familiaridade e facilidade de uso com as mídias na educação }\end{array}$ & $81 \%$ & $71 \%$ \\
\hline $\begin{array}{l}\text { aumentaram } \\
\text { Meu interesse por utilizar mídias na educação aumentou }\end{array}$ & $83 \%$ \\
\hline
\end{tabular}

Fonte: dados da pesquisa (2015)

Pelas respostas, os professores cursistas demonstraram ter ampliado sua compreensão sobre as mídias na educação e sua familiaridade e interesse por começar a utilizá-las nas suas práticas docentes. Esses dados embasaram a disciplina oferecida em 2014, atualizada para incluir as novas mídias que estavam começando a se incorporar na vida pessoal tanto dos professores como dos alunos, tais como smartphones e tablets.

\section{Letramentos e uso das mídias pelos professores participantes da disciplina de 2014-2 - O Uso de Mídias Digitais na Prática Docente}

No final do segundo semestre de 2014 foi oferecida a disciplina: "O Uso de Mídias Digitais na Prática Docente" para os novos professores da UFSC, de modo presencial e a distância, com cinco turmas, para 156 professores recém-concursados, atuantes em todos os quatro campi da universidade. Como havia 378 professores efetivos da universidade em período probatório, essas turmas representaram cerca de $40 \%$ da demanda por formação atendida de uma vez.

Das turmas do curso oferecidas dentro do Moodle, uma era semipresencial, com aulas quinzenais presenciais, e as restantes a distância, ministradas totalmente pelo ambiente virtual e por encontros por hangout (o chat que permite imagem e som como uma videoconferência do Google+). Vale ressaltar que a professora ministrou a disciplina sem apoio de monitoria ou tutoria e que 140 professores alcançaram o certificado de conclusão, obtido pela participação em $75 \%$ das atividades propostas. Esses números demonstram por si o interesse e a dedicação dos docentes para com o compromisso do curso.

Em relação à anterior, a ementa de 2014 continha uma atualização para mídias digitais e incluía os alunos e a noção de práticas docentes: Novos paradigmas do conhecimento e desafios para uma nova prática educacional. Mídia e Educação: Comunicação, Linguagens e Aprendizagem. Os novos papéis do professor e dos alunos diante das mídias digitais. O uso 
de Mídias Digitais em práticas docentes. O desenvolvimento de atividades de aprendizagem com uso de mídias digitais.

No início da disciplina, da mesma maneira que em 2011, foi pedido aos professores que preenchessem um questionário on-line para traçar seu perfil midiático. Durante o mês de setembro de 2014, responderam ao questionário 159 professores. Destes, $78 \%$ já tinham utilizado o Moodle no ensino presencial, mas mesmo assim, 66\% consideravam que não tinham experiência na docência on-line. Pelo perfil geral, com relação ao uso das mídias, os professores se mostraram confiantes, otimistas, abertos a novas ideias, seguros e dispostos a rever e revisar seu modo de ensinar, como se pode ver na Tabela 2. A curva de adoção (ROGERS, 1983) transparece, pois os inovadores (33\%) são os primeiros a experimentar, enquanto que $57 \%$ só experimenta depois de outros usarem com sucesso.

Tabela 2 - Percepção sobre perfil midiático

\begin{tabular}{|l|c|}
\hline Afirmação sobre uso das mídias & Concordância \\
\hline $\begin{array}{l}\text { Você se sente confiante diante da crescente inclusão das mídias digitais na } \\
\text { educação, e sua capacidade de adaptar-se a usá-las de forma eficaz? }\end{array}$ & $82 \%$ \\
\hline $\begin{array}{l}\text { Eu costumo experimentar uma nova tecnologia, depois que eu tenha visto } \\
\text { outros usá-la com sucesso }\end{array}$ & $57 \%$ \\
\hline $\begin{array}{l}\text { Normalmente eu sou um dos primeiros entre os meus pares para experimentar } \\
\text { uma nova tecnologia }\end{array}$ & $33 \%$ \\
\hline $\begin{array}{l}\text { Eu me sinto confiante no uso de mídias digitais em minha prática docente } \\
\text { Eu me sentiria confortável ministrando uma disciplina híbrida ou } \\
\text { semipresencial que inclui tanto componentes on-line como face a face. }\end{array}$ & $70 \%$ \\
\hline $\begin{array}{l}\text { Eu me sentiria confortável em ministrar uma disciplina totalmente on-line. } \\
\text { Em geral eu estou confiante de que posso ensinar de forma eficaz. }\end{array}$ & $50 \%$ \\
\hline $\begin{array}{l}\text { Estou confiante em tentar novas abordagens de ensino. } \\
\text { Eu tenho um plano claro quando eu vou ensinar. }\end{array}$ & $85 \%$ \\
\hline $\begin{array}{l}\text { Mesmo se algo der errado na minha prática docente, eu sou capaz de superar } \\
\text { os desafios. }\end{array}$ & $90 \%$ \\
\hline $\begin{array}{l}\text { Eu costumo pedir ajuda e apoio em termos de meu ensino, quando necessito. } \\
\text { Estou disposto em rever e revisar os conteúdos e as práticas de ensino em } \\
\text { minhas disciplinas }\end{array}$ & $90 \%$ \\
\hline $\begin{array}{l}\text { Estou confiante em rever e revisar as atividades de aprendizagem em minhas } \\
\text { disciplinas. }\end{array}$ & $94 \%$ \\
\hline
\end{tabular}

Fonte: dados da pesquisa (2015)

Muito se poderia discutir os resultados mostrados na Tabela 2, mas chama atenção que a ideia de confiança apresentada aos professores aparece de forma positiva, a maioria com índices superiores a $80 \%$. Os únicos pontos abaixo dessa autoconfiança estavam na avaliação quanto ao próprio perfil de não ser um inovador (33\%), mas esperar que outros testem (57\%). 
Apenas os novos modelos de disciplina híbrida (50\%) ou totalmente online (25\%) abalavam a segurança baseada nas práticas presenciais.

Esse otimismo apareceu também nas opções mais assinaladas para os benefícios que o uso de mídias digitais na prática docente poderia trazer para professores e alunos: "O acesso a uma gama maior de recursos" (83\%), "Aumentar a comunicação entre os estudantes, entre os colegas de uma turma" (73\%), "Favorecer o ensino e o acompanhamento dos resultados da aprendizagem" (72\%) e "Oferecer suporte para a aprendizagem 24 horas por dia, toda a semana (58\%)".

No entanto, com relação à prática docente com as mídias, as respostas mostraram que as opções não eram muitas e o repertório midiático estava baseado num pequeno cardápio. Metade dos professores já havia publicado documentos no Moodle e usava vídeos do Youtube em sala de aula mensalmente (20\%), semanalmente (20\%) ou diariamente (10\%). No entanto, $40 \%$ nunca tinham usado o Fórum para questões e $60 \%$ para debate, $77 \%$ nunca tinha usado o Chat, $89 \%$ não usavam wiki, blog ou glossário (84\%), ou jogos eletrônicos (86\%) ou mídias sociais $(66 \%)$, dentre as ferramentas ou programas menos conhecidos citadas no questionário.

Esse descompasso entre o otimismo demonstrado na Tabela 2 e a abertura para novas experiências e a pouca variedade de ferramentas na prática pedagógica pode estar ligado à consciência de seus letramentos, parciais e em constante mudança. Tanto que, ao responder como classificavam a habilidade e a eficácia pessoais no uso das ferramentas indicadas acima na própria prática docente, os professores se mostraram menos otimistas: $35 \%$ pobre, $33 \%$ média, $31 \%$ boa. Por outro lado, ao responder sobre habilidades específicas, a confiança inicial se mostrou outra vez: $86 \%$ não tinha nenhuma dificuldade em usar um buscador para pesquisa; escrever utilizando um editor de texto ou enviar email (94\%), preparar apresentações ou slides usando um editor de apresentações (85\%); participar de fóruns de discussão on-line (68\%); baixar e instalar softwares, programas de computador ou usar planilha de cálculo (56\%). A habilidade para utilizar as ferramentas do Moodle também era percebida como alta: pouca (44\%) ou nenhuma (18\%) dificuldade.

Esses dados mostram que algumas ferramentas e linguagens já estavam incorporadas, principalmente a produção de texto ou a de visualização de vídeos, mas ainda faltavam outras experiências, especialmente às voltadas ao som e à imagem. As diferenças no letramento apareceram quando $33 \%$ assinalaram "Nunca realizei esta atividade" para criar ou atualizar blogs e páginas na Internet e $20 \%$ para editar em aplicativos multimídia, de som e imagem. Essa última questão mostrou uma divisão forte entre os professores, pois $55 \%$ assinalaram pouca $(26 \%)$ ou nenhuma dificuldade $(29 \%)$. 
No final da disciplina, em dezembro de 2014, foi pedido aos professores que avaliassem as atividades, as ferramentas apresentadas e o quanto tinham aprendido e aplicado nas práticas docentes ainda no mesmo semestre letivo. Mesmo que 140 tenham conseguido o certificado de conclusão por terem alcançado a frequência necessária, responderam ao questionário on-line apenas 91 cursistas, o que pode estar relacionado às dificuldades comuns ao final do semestre letivo para a atividade docente.

Quando perguntados se se sentiam mais confiantes diante da crescente inclusão das mídias digitais na educação, e sua capacidade de adaptar-se a usá-las de forma eficaz em sua sala de aula, $79 \%$ concordou. Com relação aos desafios que continuavam a considerar como empecilho para a adoção ou desenvolvimento de práticas didáticas com uso de mídias digitais, houve uma diversidade de respostas. A restrição mais citada (56\%) foi o tempo, mostrando um panorama de excesso de trabalho, o excesso de alunos por turma (40\%), a falta de interesse dos alunos (33\%) e encontrar ou aplicar apropriadamente o conteúdo ou recursos online (30\%). Chama atenção que dentre as opções menos citadas estavam o acesso e a sua capacidade de uso (14\%), a falta de conhecimento sobre as possibilidades de uso (16\%), a relevância do ensino on-line para sua prática (13\%) e não saber quais as tarefas de aprendizagem são as mais adequadas para uma abordagem on-line (11\%). Dessa maneira, os professores consideraram como empecilhos importantes outras questões do cotidiano docente, minimizando sua própria falta de conhecimento ou de disponibilidade para uso.

Na pergunta dissertativa sobre quais mídias digitais tinham usado (ou pretendiam usar) em sala de aula, houve uma quantidade significativa de respostas e a citação de muitas opções, algumas associadas ao que tinham utilizado na disciplina, como o hangout e webinar. As palavras mais citadas mostram as muitas mídias e termos novos citados nas respostas: além do Moodle e vídeos, apareceram junto com "compartilhamento" e "curadoria" algumas ferramentas diferentes. Na mesma incidência, os nomes que apareceram foram: Prezi, Moovly, Mendeley, Stoop, Chat, Dropbox, Scholar, Blogger, Scoop, Slideshare, Hangout, Creative Commons, Share, Skype. Esta lista serve como um indício das experiências inovadoras que os professores estavam incorporando ou pelo menos considerando como possibilidade de utilizar em suas práticas a partir da disciplina. Essas respostas coincidem com o depoimento da professora ministrante durante o curso. Segundo ela, a cada aula os professores traziam exemplos ou comentavam sobre as experiências que estavam fazendo em suas práticas. No entanto, apesar de positivos, esses dados não permitem afirmar como a formação alterou os letramentos e a dinâmica das aulas dos cursistas. 


\section{Considerações finais}

O objetivo geral desta pesquisa foi identificar o perfil midiático dos professores universitários e como a formação continuada conseguiu alterar seus letramentos a partir de duas ofertas de disciplinas. A pesquisa identificou os fatores considerados pelos professores para adotar ou refutar as mídias e o Moodle em suas práticas didáticas. Os principais fatores positivos foram: a existência de iniciativas pessoais e a consciência de que as mídias agregam valor ao processo educacional. Dentre os negativos, a 'falta' apareceu como palavra geradora: falta de conhecimento das possibilidades didáticas de tais recursos, de ofertas de cursos específicos mais personalizados às suas demandas, de apoio institucional com equipes permanentes de orientação para o trabalho extra que gera e que não é considerado na cargahorária remunerada. Os docentes se mostraram mais midiáticos na vida pessoal e nas questões administrativas do que na prática pedagógica, por terem bom conhecimento dos recursos digitais disponíveis na web, mas pouco saberem dos recursos específicos do Moodle, pois a expressiva maioria fazia uso apenas das três ferramentas básicas: arquivos (repositório), entrega de tarefas e fórum de discussão.

A pesquisa mostrou ainda uma diferença entre as duas turmas investigadas. Os docentes de 2014 se mostraram mais confiantes e dispostos a experimentar novas ferramentas e linguagens do que os de 2011, o que denota uma maior presença das mídias digitais em seus cotidianos. Os dados levantados nos perfis e nas avaliações das disciplinas em dois momentos diferentes evidenciou o processo de mudança de um professor não mais resistente, avesso a experimentações e a novas maneiras de ensinar e realizar sua prática pedagógica e midiática, tradicional e fechado em sua rotina. O professor que apareceu em transição nas duas pesquisas está aberto às inovações, tem confiança e disposição para aprender novas maneiras de ensinar com as mídias. A conclusão importante é a de que, apesar deles terem apontado várias faltas que lhes são externas, a mais relevante é a do apoio institucional que considere não apenas o trabalho extra que representa a inclusão das mídias mas que, principalmente, ofereça cursos diferenciados, com equipe de orientação permanente e de fácil acesso, condições propícias para a ampliação dos letramentos dos professores para que sejam desafiados e recebam informações úteis em práticas pedagógicas significativas. Infelizmente, essa é ainda a maior falta da formação docente para as mídias exemplificada pelo caso estudado. 
AGRADECIMENTOS: Agradecemos ao CNPq pela Bolsa Produtividade (PQ) que permitiu a realização desta pesquisa.

\section{REFERÊNCIAS}

CRUZ, D. M. Mediação pedagógica. In: MILL, Daniel. (org). Dicionário Crítico de Educação e Tecnologia. 1a. ed. Campinas, SP: Papirus, 2018, p. 387-390.

CRUZ, D. M. Letramento midiático na educação a distância. In: FIDALGO, F. S. R. et al. (Org.). Educação a distância: meios, atores e processos. 1ed. Belo Horizonte: CAED UFMG, v. 1, p. 85-93, 2013.

CRUZ, D. M. O professor midiático no ensino superior: Inovação, linguagens e formação (práticas e reflexões). (Relatório de Pesquisa). CNPq, 58p, 2015.

BUCKINGHAM, D. Cultura Digital, Educação Midiática e o Lugar da Escolarização. Revista Educação Real. Porto Alegre, v. 35, n. 3, p. 37-58, set/dez, 2010. Disponível em: https://goo.gl/bhr6oE. Acesso em: 19 ago. 2017.

KENSKI, V. M. A urgência de propostas inovadoras para a formação de professores para todos os níveis de ensino. In: Revista Diálogo. v. 15, n. 45, Curitiba, 2015.

LEMKE, J. L. Letramento metamidiático: transformando significados e mídias. Trab. linguist. apl., Campinas, v. 49, n. 2, Dec. 2010. Disponível em: http://www.scielo.br/pdf/tla/v49n2/09.pdf. Acesso em: 9 set. 2017.

PIMENTA, S. G. Saberes pedagógicos e atividade docente. São Paulo: Cortez, 2009.

ROGERS, E. M. Diffusion of inovations. New York: the Free Press, 1983.

ROJO, R. H. R. Multiletramentos na escola. São Paulo: Parábola Editorial, 2012.

ZEICHNER, K. M. A formação reflexiva de professores: ideias e práticas. Lisboa:

Educacão, 1993.

\section{Como citar este artigo:}

CRUZ, Dulce Márcia. Letramentos e mídias na formação continuada de professores. Revista Ibero-Americana de Estudos em Educação, Araraquara, v. 14, n. 4, p. 2175-2188, out./dez., 2019. e-ISSN: 1982-5587. DOI: https://doi.org/10.21723/riaee.v14i4.10954

Data de Submissão: 24/05/2018

Revisões requeridas: 15/08/2018

Aceite em: 20/11/2018

Publicado em: 01/09/2019 